\title{
Pharyngeal Stripping Wave Present and Complete
}

National Cancer Institute

\section{Source}

National Cancer Institute. Pharyngeal Stripping Wave Present and Complete. NCI

Thesaurus. Code C127311.

A finding of a pharyngeal stripping wave present and complete. 